\title{
Inhibition of pyruvate dehydrogenase kinase-1 by dicoumarol enhances the sensitivity of hepatocellular carcinoma cells to oxaliplatin via metabolic reprogramming
}

\author{
HUADAN XU ${ }^{1}$, YICHUN HE ${ }^{2}$, JIAOYAN MA ${ }^{1}$, YUANXIN ZHAO ${ }^{1}$, \\ YANAN LIU $^{1}$, LIANKUN SUN ${ }^{1}$ and JING SU ${ }^{1}$ \\ ${ }^{1}$ Key Laboratory of Pathobiology, Ministry of Education, Department of Pathophysiology, \\ College of Basic Medical Sciences, Jilin University; ${ }^{2}$ Department of Neurosurgery, \\ China-Japan Union Hospital, Jilin University, Changchun, Jilin 130021, P.R. China
}

Received January 20, 2020; Accepted June 22, 2020

DOI: 10.3892/ijo.2020.5098

\begin{abstract}
The Warburg effect is a unique metabolic feature of the majority of tumor cells and is closely related to chemotherapeutic resistance. Pyruvate dehydrogenase kinase 1 (PDK1) is considered a 'switch' that controls the fate of pyruvate in glucose metabolism. However, to date, to the best of our knowledge, there are only a few studies to available which had studied the reduction of chemotherapeutic resistance via the metabolic reprogramming of tumor cells with PDK1 as a target. In the present study, it was found dicoumarol (DIC) reduced the phosphorylation of pyruvate dehydrogenase (PDH) by inhibiting the activity of PDK1, which converted the metabolism of human hepatocellular carcinoma (HCC) cells to oxidative phosphorylation, leading to an increase in mitochondrial reactive oxygen species ROS (mtROS) and a decrease in mitochondrial membrane potential (MMP), thereby increasing the apoptosis induced by oxaliplatin (OXA). Furthermore, the present study elucidated that the targeting of PDK1 may be a potential strategy for targeting metabolism in the chemotherapy of HCC. In addition, DIC as an 'old drug' exhibits novel efficacy, bringing new hope for antitumor therapy.
\end{abstract}

\section{Introduction}

Hepatocellular carcinoma (HCC) is the second most common malignant tumor with the highest morbidity and mortality (1).

Correspondence to: Dr Liankun Sun or Dr Jing Su, Key Laboratory of Pathobiology, Ministry of Education, Department of Pathophysiology, College of Basic Medical Sciences, Jilin University, 126 Xinmin Street, Changchun, Jilin 130021, P.R. China E-mail:sunlk@jlu.edu.cn

E-mail: sujing@jlu.edu.cn

Key words: apoptosis, glucose metabolism, hepatocellular carcinoma, pyruvate dehydrogenase kinase 1, Warburg effect, chemotherapeutic resistance
Oxaliplatin (OXA), as a platinum-based chemotherapeutic agent (2), has exhibited efficacy in the treatment of HCC; however, the majority of hepatobiliary cancer guidelines do not recommend the use of platinum drugs as first-line treatment due to the low sensitivity of HCC these drugs (3-6). A number of studies performed using established cancer cell lines have demonstrated that resistant cells are characterized by aerobic glycolysis and lactate levels, a by-product of glycolysis; these levels are enhanced in drug-resistant or metastatic cancers, suggesting that the Warburg effect in these cancers may reflect metabolic adaptations associated with the development of resistance to chemotherapy (7). The study by Fekir et al indicated that the upregulation of pyruvate dehydrogenase kinase (PDK) 4 was associated with chemoresistance that could be successfully reversed by the PDK4 inhibitor, dichloroacetate (DCA), in 4 HCC cell lines (8). The study by Choiniere et al demonstrated that tumor cells which have a more vigorous metabolism were more sensitive to changes in the metabolic mode; in addition, the metabolism of HCC cells derived from liver cells is particularly strong (9). Therefore, chemotherapy combined with therapies that target tumor cell metabolism may hold great potential for the treatment of HCC.

Tumor cells, including HCC cells, exhibit a unique form of metabolism, known as the Warburg effect (10). Although the Warburg effect (aerobic glycolysis) of tumor cells was discovered a hundred years ago, the mechanisms of its occurrence have not yet been fully elucidated (11). PDK1, as a key regulator in the aerobic glycolysis of tumor cells, phosphorylates the E1 subunit of pyruvate dehydrogenase (PDH) at Ser232, leading to its inactivation (12). Inactivated PDH fails to catalyze the conversion of pyruvate into acetyl-CoA, thus preventing pyruvate from entering tricarboxylic acid cycle (TCA) $(12,13)$. In other words, PDK1 may regulate cellular glucose metabolism by controlling the conversion of pyruvate. Wang et al confirmed that the expression of PDK1 in HCC tissues was significantly higher than that of adjacent normal tissues by immunohistochemical staining (14). The results of the study by Battello et al revealed that HCC cells exhibited an enhanced transcription and expression of hypoxia-inducible factor (HIF)-1 $\alpha$ under normal oxygen conditions through the 
inflammatory cytokine, oncostatin M (OSM), resulting in the HIF-1-regulated PDK1 expression in HCC cells (15), indicating that PDK1 plays an important role in the process of HCC. In a previous study by the authors, it was demonstrated that dicoumarol (DIC) can bind to the lipoamide binding pocket of PDK1's, exerting a more effective selective inhibitory activity compared to the classic inhibitor of PDK1, sodium dichloroacetate (DCA), and inhibits glycolysis in human ovarian cancer cells (16).

Therefore, the present study aimed to target PDK1 to explore its significance for the metabolic transformation of HCC cells and its potential for enhancing the sensitivity of chemotherapeutic drugs. Furthermore, the present study proposes a possible mechanism of the Warburg effect, providing an effective strategy for determining the role of oxidative phosphorylation and glycolysis in tumors, such as HCC.

\section{Materials and methods}

Reagents and antibodies. DIC (Selleck Chemicals) was dissolved in $2 \%$ dimethyl sulfoxide (DMSO). 3-(4,5-Dimethylthiazol-2-yl)-2,5-diphenyltetrazolium bromide (MTT), N-acetyl-L-cysteine (NAC), Hoechst 33342 and anti-p-PDHE1A (s232) antibody (SAB1305601) were purchased from Sigma-Aldrich; Merck KGaA. Anti- $\beta$-actin antibody (sc-81760) was from Santa Cruz Biotechnology, Inc. Anti-PDH (ab67592) and anti-PDK1 (ab202468) were from Abcam.

Analysis of combined drug effects. Drug synergy was determined by the combination index method derived from the median-effect principle of Chou and Talalay. Data obtained from the growth inhibitory experiments of DIC and OXA were used to perform these analyses. The resulting combination index (CI) theorem of Chou-Talalay offers quantitative definition for additive effect $(\mathrm{CI}=1)$, synergism $(\mathrm{CI}>1)$, and antagonism $(\mathrm{CI}>1)$ in drug combinations $(17,18)$.

Inhibition of PDK1 by shRNA. Short hairpin (sh)RNA targeting PDK1 and scrambled-shRNA (scr-shRNA) were purchased from GenePharma. The PDK1 shRNA sequence was as follows: 5'-CTT-CGG-ATC-AGT-GAA-TGC-TTG-3', the scrambled-shRNA (scr-shRNA) sequence, used as a negative control, was 5'-GTT-CTC-CGA-ACG-TGT-CAC-GT-3'. Following adherence, the cells were transfected with the shRNA plasmid using TurboFect ${ }^{\mathrm{TM}}$ transfection reagent (Thermo Fisher Scientific, Inc.) according to the manufacturer's protocol. Cells were plated in 6-well plates or 96-well plates and transfected the following day with 4 or $0.2 \mu \mathrm{g}$ of PDK1-shRNA or scr-shRNA using 6 or $0.4 \mu \mathrm{l}$ of transfection reagent, respectively. After $48 \mathrm{~h}$, cells were collected for use in the indicated assays.

Mice. Male BALB/c-nu mice aged 6 weeks old and weighing approximately $15 \mathrm{~g}$ each were purchased from Beijing Vital River Laboratory Animal Technology Co., Ltd. They were kept at temperature $\left(22-24^{\circ} \mathrm{C}\right)$ with a stable humidity $(55 \pm 15 \%)$ with free access to food/water in a $12 \mathrm{~h} / 12 \mathrm{~h}$ light/dark cycle and housed in specific pathogen-free conditions at Jilin University (19). A total of 5x106 SNU-449 cells were subcutaneously injected into the backs of the mice. After 7 days, when the tumor volume reached approximately $100 \mathrm{~mm}^{3}$, the nude mice were randomly divided into 4 groups and were administered treatment intraperitoneally (i.p.) every day (Fig. 3A). The control group, administered $200 \mu 1$ saline; the DIC group, administered $25 \mathrm{mg} / \mathrm{kg}$ DIC; the OXA group, administered 200 mg/kg OXA (Shandong New Time Pharmaceutical Co., Ltd.); and the OXA + DIC group, administered the corresponding drugs indicated above. All animal experiments were performed in accordance with the National Guidelines for Experimental Animal Welfare and with approval of the Animal Welfare and Research Ethics Committee at Jilin University (Changchun, China).

Cells and cell culture. The human HCC cell lines, SNU-387 and SNU-449, were purchased from the Chinese Academy of Medical Sciences. The two cell lines were cultured in RPMI-1640 medium containing 10\% fetal bovine serum and $1 \%$ antibiotics (HyClone; GE Healthcare Life Sciences), and were grown in a humidified cell culture incubator containing $5 \% \mathrm{CO}_{2}$ and $95 \%$ air at $37^{\circ} \mathrm{C}$.

Cell viability assay. The in vitro cell viability was examined using the standard MTT assay, as previously described (20). Briefly, the SNU-387 and SNU-449 cells were seeded in 96-well plates at 8,000 cells/well. The following day, increasing concentrations $(0,4,16,64$ and $256 \mu \mathrm{M})$ of OXA with or without DIC were added to each well, and the plates were then incubated at $37^{\circ} \mathrm{C}$ for $24 \mathrm{~h}$. For the SNU-449 cells, the following day, increasing concentrations of OXA and DIC with or without pre-treatment with $5 \mathrm{mM} \mathrm{NAC} \mathrm{for} 1 \mathrm{~h}$ were added to each well, and the plates were incubated at $37^{\circ} \mathrm{C}$ for $24 \mathrm{~h}$. Subsequently, $10 \mu \mathrm{l}$ of $5 \mathrm{mg} / \mathrm{ml}$ MTT reagent (Sigma-Aldrich; Merck KGaA) in phosphate-buffered saline (PBS) were added to each well, and the plate was incubated at $37^{\circ} \mathrm{C}$ for an additional $4 \mathrm{~h}$. The formazan crystals were dissolved in $150 \mu \mathrm{l}$ of DMSO, and after the plate was shaken for $10 \mathrm{~min}$, the optical density at $570 \mathrm{~nm}$ was recorded using a multifunctional microplate reader (BMG Labtech).

Western blot analysis. SNU-449 and SNU-387 cells were treated with DIC (25 $\mu \mathrm{M})$, OXA (64 and $256 \mu \mathrm{M})$, OXA (64 and $256 \mu \mathrm{M})$ and DIC $(25 \mu \mathrm{M})$ for $24 \mathrm{~h}$. The cells were lysed in cold RIPA buffer containing $1 \%$ PMSF and $1 \% \beta$-mercaptoethanol, and the lysate was collected by centrifugation at $12,000 \mathrm{x} \mathrm{g}$ for $10 \mathrm{~min}$ at $4^{\circ} \mathrm{C}$. Total protein in each sample was quantified using the Bio-Rad protein reagent (Bio-Rad Laboratories, Inc.). Approximately $50 \mu \mathrm{g}$ of total protein from each sample was denatured at $95^{\circ} \mathrm{C}$ for $10 \mathrm{~min}$, separated by $12-15 \%$ sodium dodecyl sulfate-polyacrylamide gel electrophoresis, and transferred onto Immune-Blot polyvinylidene fluoride membranes (Bio-Rad Laboratories, Inc.). After blocking in 5\% (w/v) non-fat milk in Tris-buffered saline for $2 \mathrm{~h}$, the membranes were incubated with specific primary antibodies $(1: 1,000)$ (indicated above in 'Reagents and antibodies') overnight at $4^{\circ} \mathrm{C}$. Following incubation of the membranes with secondary antibodies [peroxidase-conjugated AffiniPure goat anti-mouse IgG (H+L; cat. no. SA00001-1), and peroxidase-conjugated AffiniPure goat anti-rabbit IgG (H+L; cat. no. SA00001-2) from ProteinTech Group, Inc. at room temperature for 1.5-2 h, the signals were detected using 
enhanced chemiluminescence reagents followed by Syngene Bio Imaging (Synoptics). The band densities were measured using Syngene Bio Imaging tools (the software was used for densitometry).

Hoechst 33342 staining assay. Morphological alterations of apoptotic cells were detected by staining the nuclear chromatin of the SNU-449 cells with Hoechst 33342. In brief, $2 \times 10^{4}$ SNU-449 cells were cultured in 24 -well plates per well at $37^{\circ} \mathrm{C}$ and treated as indicated for an additional $24 \mathrm{~h}$. The cells were washed with cold PBS and fixed using $4 \%(\mathrm{w} / \mathrm{v})$ paraformaldehyde for $15 \mathrm{~min}$. The plates were then incubated with $1 \mu \mathrm{g} / \mathrm{ml}$ Hoechst 33342 for $10 \mathrm{~min}$ and observed under a fluorescence microscope (IX-71; Olympus Corp.).

Apoptosis assay. A total of $3 \times 10^{4}$ SNU-387 or SNU-449 cells per well were seeded into 6-well plates and divided into 7 groups according to the treatments they received: The control (unstained), control (stained), DIC (25 $\mu \mathrm{M})$, OXA (64 $\mu \mathrm{M}$ or $256 \mu \mathrm{M})$, co-treated with DIC $(25 \mu \mathrm{M})$ and OXA (64 or $256 \mu \mathrm{M})$. Following the 24 -h treatment, apoptosis was measured by staining the cells with Annexin $\mathrm{V}$ and propidium iodide (PI) using the FITC Annexin V Apoptosis Detection kit from BD Pharmingen (BD Biosciences). The cells were analyzed on a C6 Flow Cytometer, and the signal was quantified using C6 Software and a Workstation Computer (BD Accuri $^{\mathrm{TM}}$ ).

Gene Expression Profiling Interactive Analysis (GEPIA). GEPIA is a newly developed interactive web server for analyzing the RNA sequencing expression data of 9,736 tumor and 8,587 normal samples from TCGA and the GTEx projects, using a standard processing pipeline $(21,22)$. GEPIA performs survival analysis based on gene expression levels.

Integrative Molecular Database of Hepatocellular Carcinoma $(N C C D B)$. NCCDB is a database of 15 curated public HCC expression datasets that cover approximately 4,000 clinical samples and develop to serve as a one-stop online resource for exploring HCC gene expression with user-friendly interfaces. Among these 15 datasets, HCCDB15 is the dataset with the largest number of samples, including $356 \mathrm{HCC}$ samples and 49 adjacent tissue samples (23).

Determination of glucose uptake and lactate production. The SNU-449 cells were treated with indicated drugs [DIC (25 $\mu \mathrm{M})$, OXA (64 and $256 \mu \mathrm{M})$, OXA (64 and $256 \mu \mathrm{M})$ and DIC $(25 \mu \mathrm{M})]$ for $24 \mathrm{~h}$, washed with PBS, and cultured in RPMI-1640 culture medium to achieve a confluency of $80 \%$. The culture medium was then collected, and the glucose and lactate concentrations were measured with a glucose assay kit and a lactate assay kit (Beyotime Institute of Biotechnology, Inc.), respectively. The data were normalized by the corresponding total protein amounts from each sample.

Oxygen consumption rate (OCR) and extracellular acidification rate $(E C A R)$ analysis. A total of $8 \times 10^{4}$ SNU-449 and SNU-387 cells were seeded into 96-well plates and incubated at $37^{\circ} \mathrm{C}$ overnight to allow adherence. The following day, various concentrations of DIC $(25$ and $50 \mu \mathrm{M})$ were added into the indicated wells. Each treatment was repeated in 3 wells. The OCR and ECAR were measured using oxygen-sensitive (Mito-Xpress) and $\mathrm{pH}$-sensitive (pH-Xtra) fluorescent probes (Luxcel Bioscience).

Measurement of reactive oxygen species (ROS) levels. The SNU-449 cells were treated with the control (unstained), control (stained with Mito SOX ${ }^{\mathrm{TM}}$ Red Mitochondrial Superoxide Indicator), DIC $(25 \mu \mathrm{M})$, OXA (64 or $256 \mu \mathrm{M})$, co-treated with DIC $(25 \mu \mathrm{M})$ and OXA $(64$ or $256 \mu \mathrm{M})$ for $24 \mathrm{~h}$, and the ROS level in each sample was then detected by cell staining with Mito SOX ${ }^{\mathrm{TM}}$ Red Mitochondrial Superoxide Indicator (Invitrogen; Thermo Fisher Scientific, Inc.), according to the manufacturer's instructions. Positive cells containing a high level of ROS were detected by the BD Accuri ${ }^{\mathrm{TM}}$ C6 Plus personal flow cytometry (BD Biosciences).

Measurement of mitochondrial membrane potential (MMP). MMP was determined by using JC-1 dye, contained within the Mitochondrial Membrane Potential Assay kit (Beyotime Institute of Biotechnology, Inc.). Following treatment with DIC $(25 \mu \mathrm{M})$, OXA (64 or $256 \mu \mathrm{M})$, co-treated with DIC $(25 \mu \mathrm{M})$ and OXA $(64$ or $256 \mu \mathrm{M})$ for $24 \mathrm{~h}$, the cells were incubated with $1 \mathrm{ml}$ of $1 \mathrm{X} \mathrm{JC}-1$ for $30 \mathrm{~min}$ at $37^{\circ} \mathrm{C}$ in the dark, and the ratio of cells positive for red fluorescence (JC-1 polymer indicating intact MMP) to those positive for green fluorescence (monomeric form of JC-1, an indicator for loss of MMP) was determined by flow cytometry using BD Accuri C6.

Immunohistochemistry. The mouse tissues were fixed in $4 \%(\mathrm{w} / \mathrm{v})$ paraformaldehyde, dehydrated in graded ethanol and embedded in paraffin. Samples were cut into $3-\mu \mathrm{m}$-thick sections using a Leica microtome (16). TUNEL staining was carried out with an In Situ Cell Death Detection kit, POD (Roche Diagnostics GmbH).

Statistical analysis. Data are expressed as the means \pm standard error (SE). Differences were analyzed using one-way analysis of variance (ANOVA) followed by Tukey's multiple comparisons test. All experiments were repeated 3 times. A value of $\mathrm{P}<0.05$ was considered to indicate a statistically significant difference. Statistical analysis was performed using SPSS 12.0 statistical software (SPSS, Inc.).

\section{Results}

PDK1 is highly expressed in HCC, and DIC inhibits PDK1 activity in SNU-449 and SNU-387 cells. In order to determine the effects of metabolic reprogramming on drug resistance in HCC cells, the present study first focused on PDK1, a 'switch' that controls pyruvate in glucose metabolism and plays an important role in the metabolic pattern of aerobic glycolysis of tumor cells (known as the Warburg effect). The expression of PDK1 in liver HCC (LIHC) was higher than that in normal liver issue (Fig. 1A) based on the data from GEPIA. In addition, patients with a high PDK1 expression exhibited a lower overall survival than patients with a low expression (Fig. 1B). Consistent results were also obtained with the HCCDB15 dataset from the HCCDB database in HCC (Fig. 1C) and in 
A

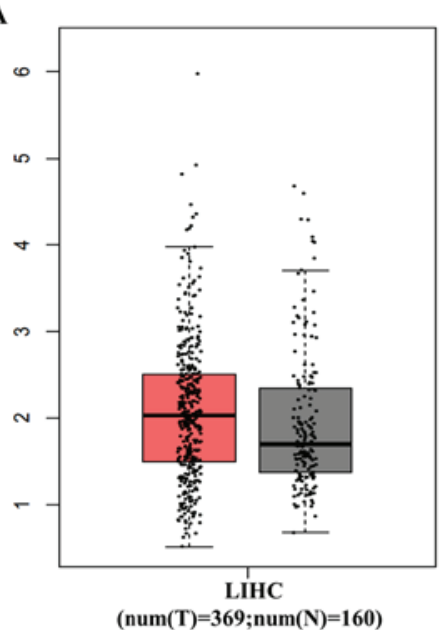

C

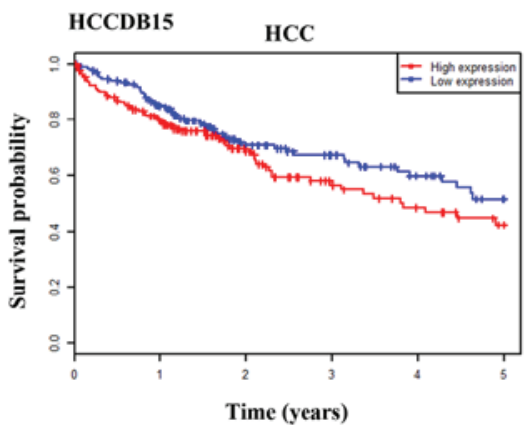

B
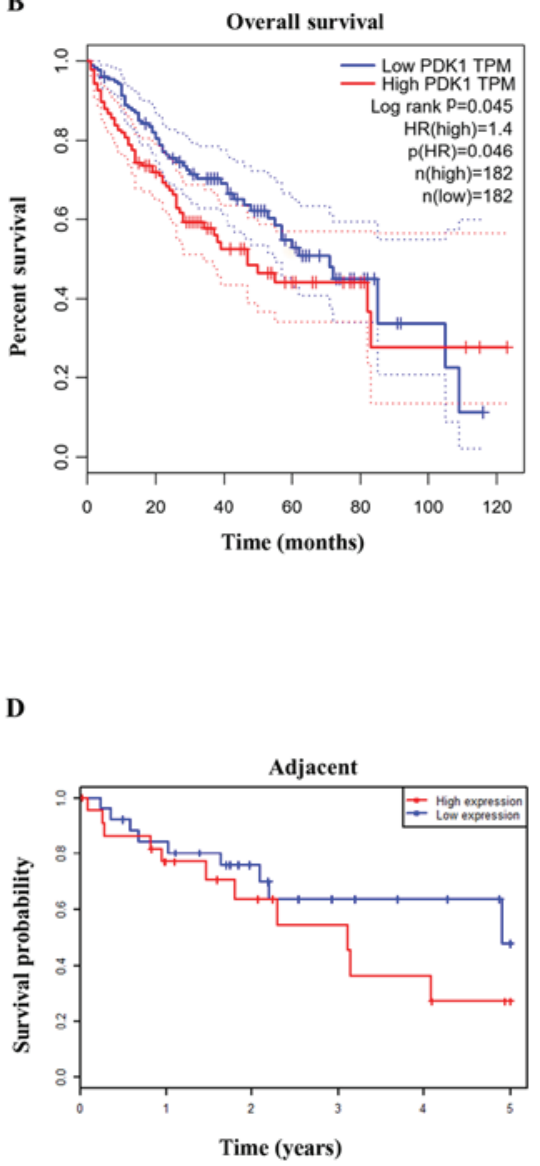

$\mathbf{E}$
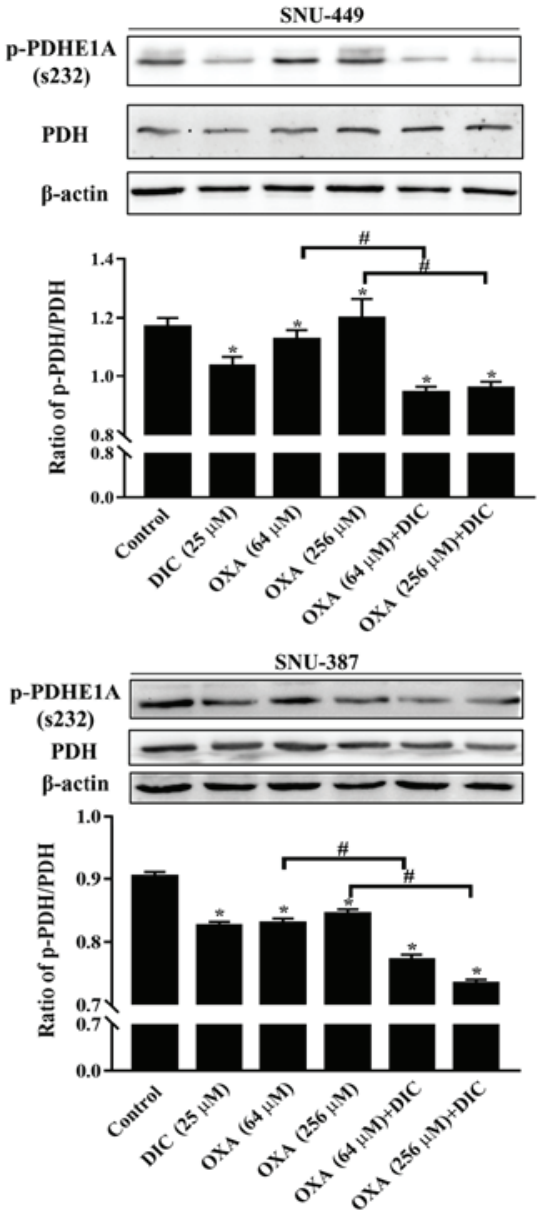

Figure 1. PDK1 is highly expressed in HCC, and DIC inhibits PDK1 activity in SNU-449 cells and SNU-387 cells. (A) Bioinformatics analysis results of the expression of PDK1 in liver hepatocellular carcinoma (LIHC) acquired from GEPIA. (B) Overall survival curve showing the significant association between PDK1 and survival in LIHC $(\mathrm{P}<0.05)$ acquired from GEPIA. The dotted lines represent the hazard ratio. (C and D) Survival probability curves showing the association between PDK1 and survival in HCC and adjacent tissues. (E) SNU-449 cells were treated with DIC (25 $\mu \mathrm{M}), \mathrm{OXA}$ (64 and $256 \mu \mathrm{M}), \mathrm{OXA}(64$ and $256 \mu \mathrm{M})$ and DIC $(25 \mu \mathrm{M})$ for $24 \mathrm{~h}$. The levels of PDH and p-PDHE1A (Ser232) were detected by western blot analysis. $\beta$-actin was used as an internal control. The lower panel represents the quantified graph of the ratio of p-PDH/PDH of the upper panel. ${ }^{*} \mathrm{P}<0.05$ vs. control; ${ }^{\sharp} \mathrm{P}<0.05 \mathrm{DIC}$ treatment vs. no DIC treatment at the same concentration of OXA. (F) SNU-387 cells were treated as described in (E). The levels of PDH and p-PDHE1A (Ser232) were detected by western blot analysis. $\beta$-actin was used as an internal control. The lower panel represents the quantified graph of the ratio of p-PDH/PDH of the upper panel. ${ }^{*} \mathrm{P}<0.05$ vs. control; ${ }^{\#} \mathrm{P}<0.05$ DIC treatment vs. no DIC treatment at the same concentration of OXA. Data are presented as the means \pm SE from 3 independent experiments. HCC, hepatocellular carcinoma; GEPIA, Gene Expression Profiling Interactive Analysis; PDK1, pyruvate dehydrogenase kinase 1; LIHC, liver hepatocellular carcinoma; DIC, dicoumarol; OXA, oxaliplatin; PDH, pyruvate dehydrogenase.

adjacent tissues (Fig. 1D). The above-mentioned results indicated that PDK1 may play an important role in the occurrence and development of HCC.

In addition, the phosphorylation of the PDK1-specific phosphorylation site (Ser232) on PDH was evaluated to assess the inhibitory effects of DIC on PDK1. It was found that the levels of phosphorylated PDH (Ser 232) in the SNU-449 (Fig. 1E) and SNU-387 cells (Fig. 1F) treated with DIC exhibited a significant decreased compared with those of the control group, consistent with previous findings by the authors obtained with human ovarian cancer cells SKOV3 and A2780 (16). Moreover, the groups treated with both OXA and DIC exhibited a significant inhibition of PDK1 activity compared with the corresponding OXA treatment group (Fig. 1E and F).

DIC and OXA synergistically inhibit tumor growth in vitro and in vivo. Subsequently, the present study verified whether combined treatment with DIC and OXA would affect tumor growth. MTT assay revealed that SNU-449 cell viability decreased following treatment with OXA $(0-256 \mu \mathrm{M})$ for $24 \mathrm{~h}$, and further decreased following combined treatment with OXA and DIC (25 $\mu \mathrm{M})$ (Fig. 2A). The trend observed in the viability of the SNU-387 cells was consistent with that of the SNU-449 cells (Fig. 2B). To further confirm this combined drug effect, the combination index (CI) of both drugs was calculated. The calculated CI was $<1$, indicating that DIC and OXA exerted a combined drug effect (Fig. 2C). However, when shRNA was used to inhibit PDK1, DIC did not enhance the inhibitory effects of OXA on the viability of 2 cell lines (Fig. 2F and G). The above-mentioned results indicate that the synergistic effects of DIC and OXA may be the result of the inhibitory effect of DIC on PDK1. An interesting point was noted: The SNU-449 cells seemed to be more sensitive to the effects of DIC (Fig. 2A and B); thus, the expression of PDK1 at the basal level was examined in both cell lines. It was found that the SNU-449 cells exhibited a higher PDK1 expression level than the SNU-387 cells 

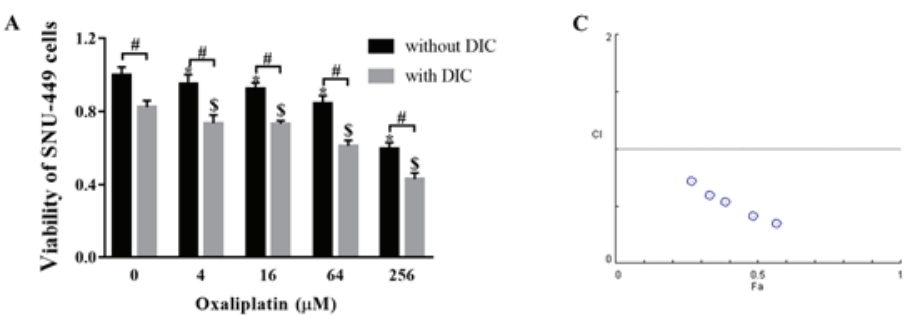

D

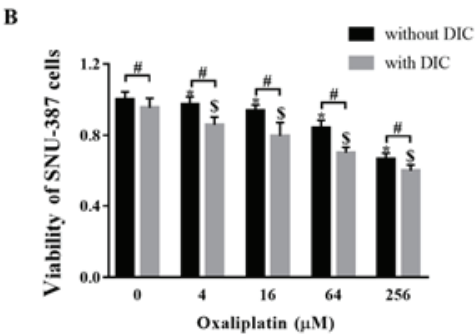

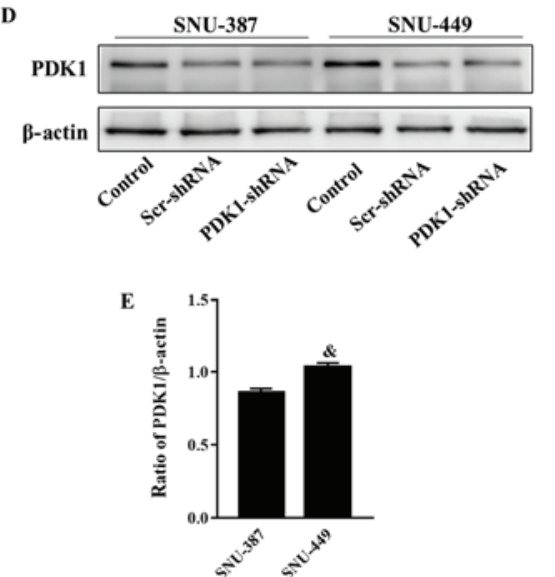
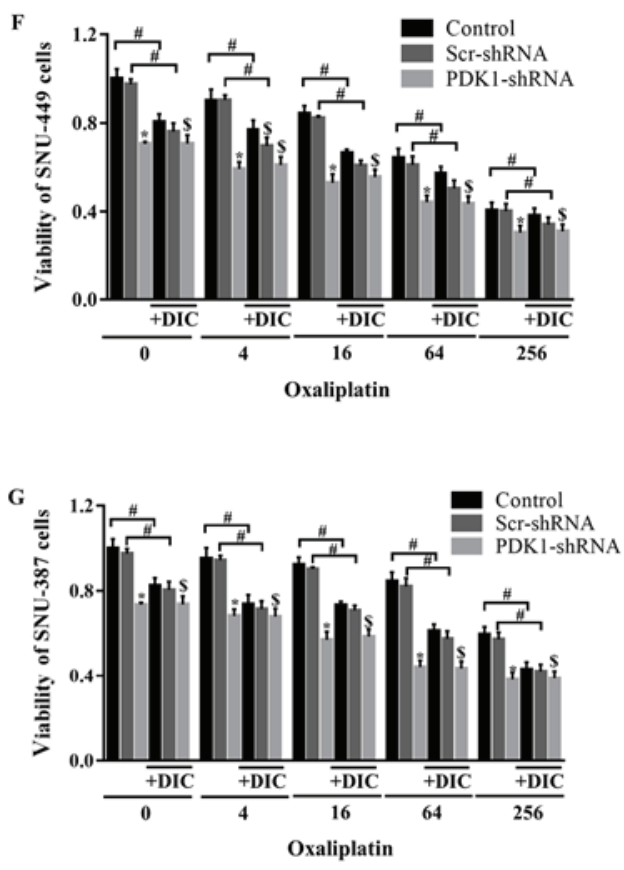

Figure 2. DIC and OXA synergistically inhibit tumor growth in vitro. (A) SNU-449 cells and (B) SNU-387 cells were treated with OXA (4, 16, 64, or 256 $\mu$ M) for $24 \mathrm{~h}$ with or without DIC $(25 \mu \mathrm{M})$ and cell viability was assayed by MTT assay. ${ }^{*} \mathrm{P}<0.05$ vs. control; ${ }^{\#} \mathrm{P}<0.05 \mathrm{DIC}$ treatment vs. no DIC treatment at the same concentration of OXA. (C) The combination index (CI) of DIC and OXA obtained from the growth inhibitory experiments, additive effect (CI=1), synergism $(\mathrm{CI}<1)$ and antagonism $(\mathrm{CI}>1)$ in drug combinations. (D) SNU-387 and SNU-449 cells were transiently transfected for $48 \mathrm{~h}$ with the shPDK1 expression vector or empty vector, and western blot analysis was performed to examine the levels of PDK1. (E) Quantified results of PDK1 in SNU-387 and SNU-449 cells. ${ }^{\star} \mathrm{P}<0.05$ SNU-449 vs. SNU-387 cells. (F) SNU-449 cells and (G) SNU-387 cells were treated with OXA (4, 16,64 or $256 \mu$ M) for 24 h with or without DIC $(25 \mu \mathrm{M})$ and treated as described in (D), and cell viability was assayed by MTT assay. ${ }^{* \$} \mathrm{P}<0.05$ vs. control. ${ }^{\#} \mathrm{P}<0.05$ DIC treatment vs. no DIC treatment at the same concentration of OXA. Data are presented as the means \pm SE from 3 independent experiments. HCC, hepatocellular carcinoma; PDK1, pyruvate dehydrogenase kinase 1; DIC, dicoumarol; OXA, oxaliplatin.
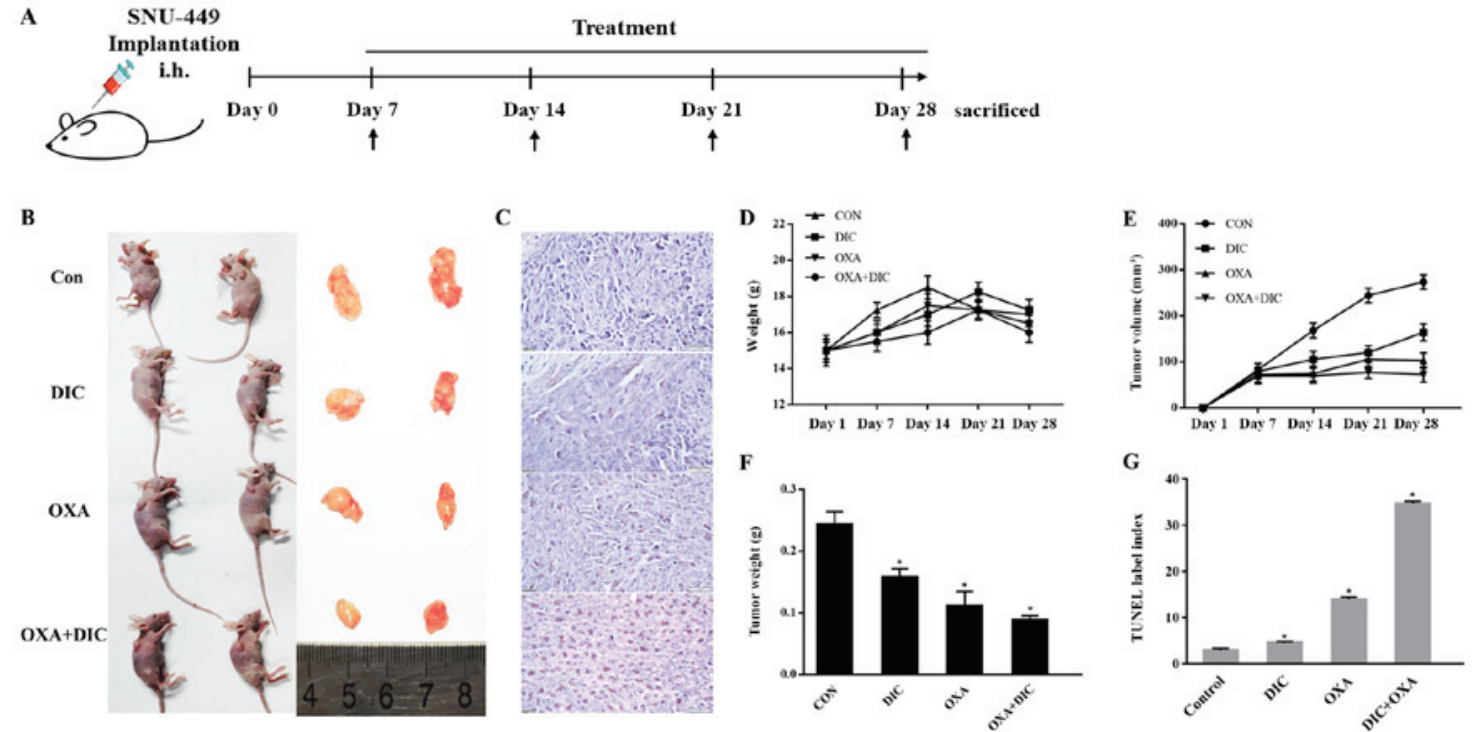

Figure 3. DIC and OXA synergistically inhibit tumor growth in vivo. (A) Timeline of treatment and measurement of tumors volume and body weights of xenograft tumor models. (B) Xenograft tumor model picture and tumor images following the administration of saline (200 $\mu 1$ ), DIC (25 mg/kg), OXA $(200 \mathrm{mg} / \mathrm{kg})$, and OXA (200 mg/kg) in combination with DIC (25 mg/kg) every day for 21 days, respectively. (C) Representative images of TUNEL assay results. (D-F) Bodyweight and tumor volume were measured every 7 days; tumor volume was determined by measuring the length and width with calipers. On day 28, mice were sacrificed and tumors were dissected, weighed and photographed. (G) Quantified results of TUNEL assay. ${ }^{*}<0.05$ vs. control. Data are presented as the means \pm SE from 3 independent experiments. DIC, dicoumarol; OXA, oxaliplatin.

(Fig. 2D and E), indicating that the difference in PDK1 levels may be the reason for the difference in the inhibition of the viability of the 2 cell lines by DIC.
This effect was further investigated in vivo. SNU-449 tumor xenografts were established in nude mice and the mice were treated with normal saline (control), DIC $(25 \mathrm{mg} / \mathrm{kg})$, 


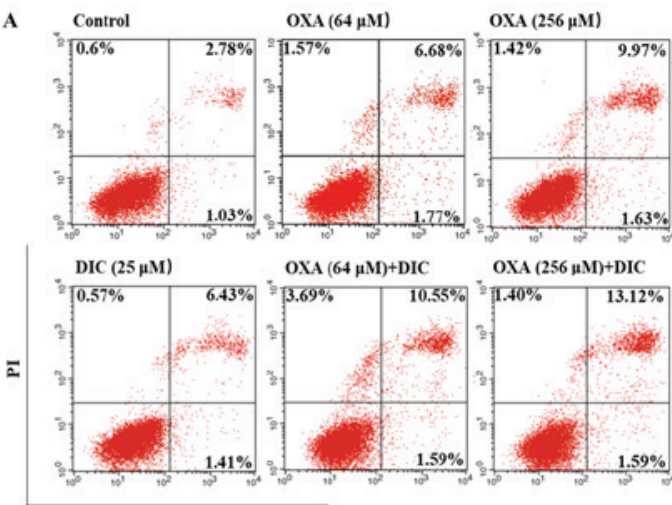

Annexin V.FITC

E Control

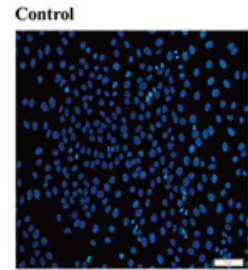

DIC (25 $\mu \mathrm{M})$

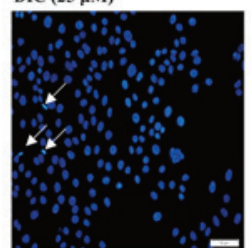

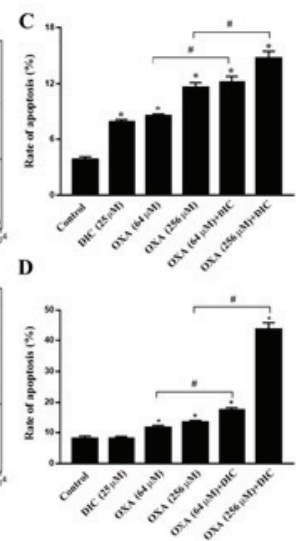

OXA (64 „M)

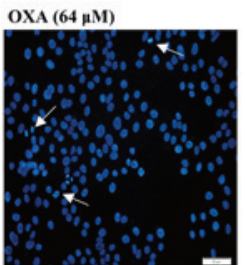

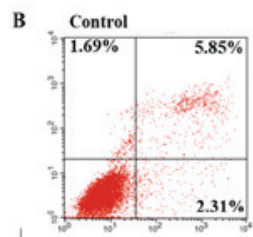

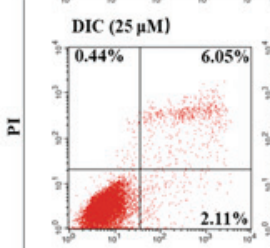

Annexin V-FITC

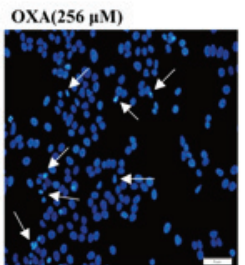

OXA $(64 \mu \mathrm{M})+\mathrm{DIC}$

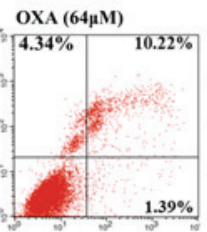

OXA (64 $\mu \mathrm{M})+$ DIC
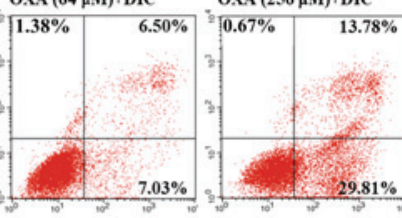

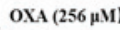

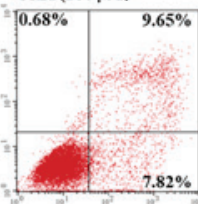

$7.82 \%$

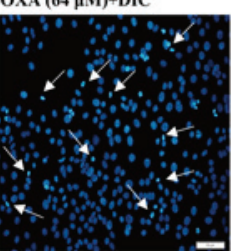

OXA $(256 \mu \mathrm{M})+\mathrm{DIC}$

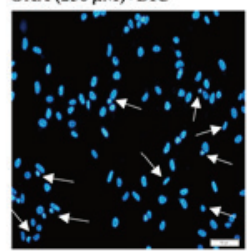

Figure 4. DIC enhances the sensitivity of HCC cells to OXA-induced apoptosis. SNU-449 cells were treated with DIC ( $25 \mu \mathrm{M})$, OXA (64 and $256 \mu \mathrm{M}), \mathrm{OXA}$ $(6$ and $256 \mu \mathrm{M})$ and DIC $(25 \mu \mathrm{M})$ for $24 \mathrm{~h}$ and then analyzed by flow cytometry with Annexin V and PI staining. Representative flow cytometry images are shown. (B) SNU-387 cells were subjected to the same treatment and then analyzed by flow cytometry with Annexin V and PI staining. Representative flow cytometry images are shown. (C) Apoptosis statistics histogram of data in (A). ${ }^{*} \mathrm{P}<0.05$ vs. control; ${ }^{*} \mathrm{P}<0.05 \mathrm{DIC}$ treatment vs. no DIC treatment at the same concentration of OXA. (D) Apoptosis statistics histogram of data in (B). ${ }^{*} \mathrm{P}<0.05$ vs. control; ${ }^{\#} \mathrm{P}<0.05$ DIC treatment vs. no DIC treatment at the same concentration of OXA. (E) Cells were treated as in (A) and then stained with Hoechst 33342 and visualized under a fluorescence microscope (x200 magnification; scale bar, $50 \mu \mathrm{m}$ ). Data are presented as the means \pm SE from 3 independent experiments. HCC, hepatocellular carcinoma; DIC, dicoumarol; OXA, oxaliplatin.

OXA (200 mg/kg), or DIC (25 mg/kg) and OXA (200 mg/kg) after 7 days (Fig. 3A). During the 21-day treatment period, the body weights of the mice from all groups did not alter significantly, suggesting that all treatments were safe for the animals (Fig. 3D). However, the tumor weight (Fig. 3E) and volume (Fig. 3F) decreased to a certain extent in the DIC and OXA groups compared with the control group, and a more pronounced decrease was observed in the group treated with both DIC and OXA (Fig. 3B, E and F). Finally, apoptosis in SNU-A449 xenografts was detected using a TUNEL assay. The results revealed significantly higher $\mathrm{TUNEL}^{+}$signals in the DIC and OXA combination group consistent with the above-mentioned results (Fig. 3C and G). These results demonstrated DIC and OXA synergistically inhibited tumor growth in vitro and in vivo.

DIC enhances the sensitivity of HCC cells to OXA-induced apoptosis. In order to clarify the mechanisms responsible for the inhibition of tumor growth observed following combined treatment with DIC and OXA, indicators of apoptosis were examined in vitro. Consistent with the results obtained in vivo, the groups treatmed with DIC and OXA alone exhibited a certain degree of apoptosis compared to the control group, as shown by Annexin V-PI staining. However, marked apoptosis was observed in the combined treatment groups of SNU-449 (Fig. 4A) and SNU-387 (Fig. 4B) HCC cells in a concentration-dependent manner, respectively. The sum of the early and late apoptotic rates of the 2 cell lines are also shown (Fig. 4C and D). In the morphological analysis, the SNU-449 cells exhibited nuclear shrinking, become round in shape and were slightly smaller than the normal cells following combined treatment with DIC and OXA for $24 \mathrm{~h}$ compared with each individual treatment, as shown by Hoechst 33342 staining (Fig. 4E). The above-mentioned results indicated that combined treatment with OXA and DIC induced the apoptosis of HCC cells.

DIC alters metabolism of HCC cells and enhances oxidative phosphorylation. Subsequently, the mechanisms through which DIC treatment increases the apoptosis of HCC cells induced by OXA were investigated. Based on the inhibition of PDK1 by DIC (Fig. 1E and F) and the important role of PDK1 in glucose metabolism of tumor cells (24), some glucose metabolism indicators of HCC cells in SNU-449 and SNU-387 were examined. Relative glucose uptake (Fig. 5A) and lactate production (Fig. 5B) were decreased in the DIC-treated group compared to the control group. Consistently, the addition of DIC $(25 \mu \mathrm{M})$ in combination with OXA also decreased relative glucose uptake (Fig. 5A) and lactic acid production (Fig. 5B) compared with the OXA group (64 and $256 \mu \mathrm{M}$ ), although OXA treatment alone exerted no significant effects and even increased lactic acid production and glucose uptake. To further examine the trend of glucose metabolism following DIC treatment, the OCR and ECAR of SNU-449 cells were examined; OCR is commonly used to indicate the occurrence of oxidative phosphorylation and ECAR is used as an indicator of glycolysis during glucose metabolism. It was found that the increase in OCR was more significant than ECAR, which was almost 10 and 30\% higher in the DIC-treated cells, respectively (Fig. 5C). In addition, the glucose uptake (Fig. 5D), lactate production (Fig. 5E) and the ratio of OCR to ECAR (Fig. 5F) in the SNU-387 cells were basically consistent with those in 

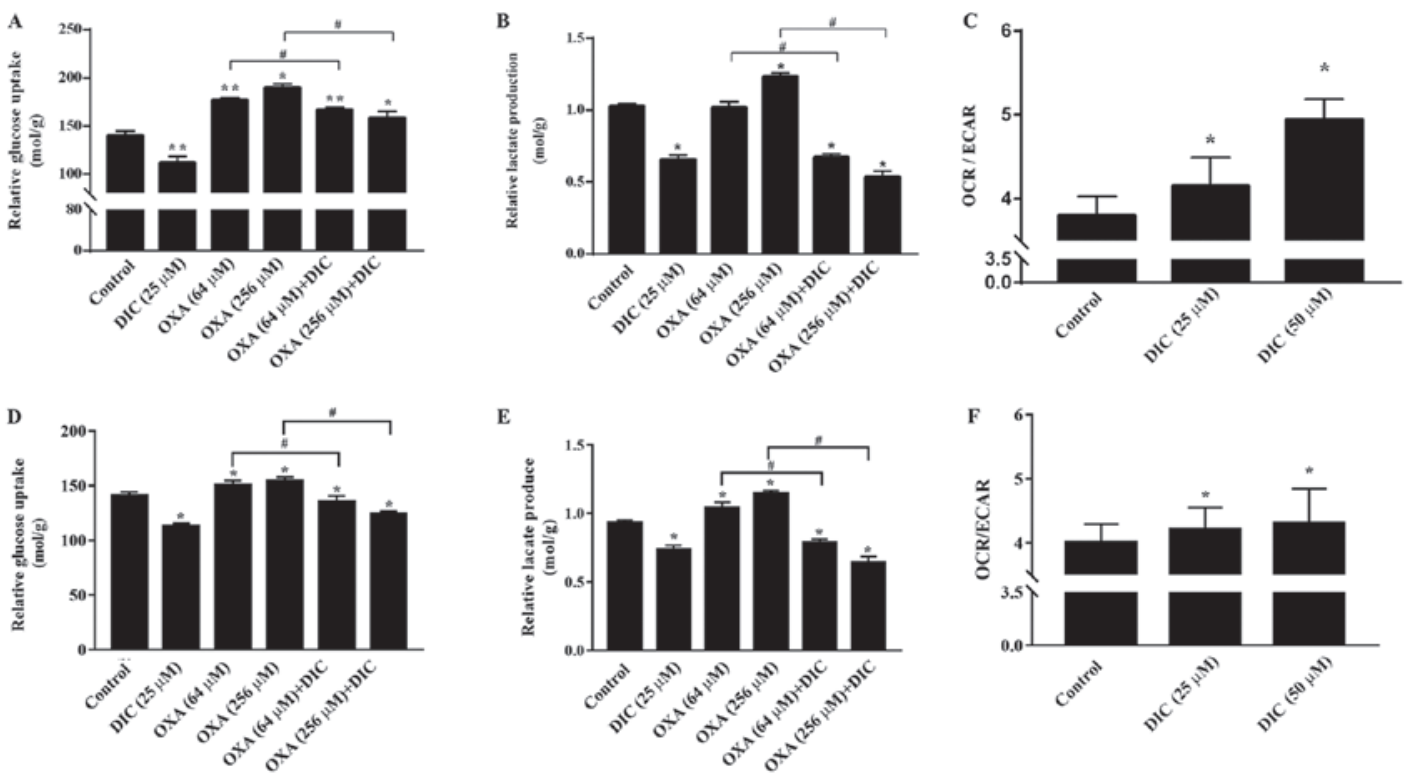

Figure 5. DIC alters metabolism of HCC cells and enhances oxidative phosphorylation. (A and B) SNU-449 cells were treated with DIC (25 $\mu \mathrm{M}$ ), OXA (64 and $256 \mu \mathrm{M})$, OXA (64 and $256 \mu \mathrm{M})$ and DIC $(25 \mu \mathrm{M})$ for $24 \mathrm{~h}$. The (A) extracellular glucose uptake and (B) lactate concentration were determined and normalized to the total protein amount. ${ }^{*} \mathrm{P}<0.05$ vs. control; ${ }^{* *} \mathrm{P}<0.01$ vs. control; ${ }^{*} \mathrm{P}<0.05$ DIC treatment vs. no DIC treatment at the same concentration of OXA. (C) SNU-449 cells were treated with DIC ( $25 \mu \mathrm{M}$ or $50 \mu \mathrm{M})$. The extracellular oxygen consumption (OCR) was immediately measured, and the extracellular acidification rate (ECAR) were detected following $3 \mathrm{~h}$ of incubation at $37^{\circ} \mathrm{C}$. The graph shows the ratio of OCR to ECAR, representing the relative proportions of oxidative phosphorylation and glycolysis. ${ }^{*} \mathrm{P}<0.05$ vs. control. (D and E) SNU-387 cells were treated as described in (A). The (D) extracellular glucose uptake and (E) lactate concentration were determined and normalized to the total protein amount. ${ }^{*} \mathrm{P}<0.05$ vs. control; ${ }^{*} \mathrm{P}<0.05 \mathrm{DIC}$ treatment vs. no DIC treatment at the same concentration of OXA. (F) SNU-387 cells were treated as described in (C). The extracellular oxygen consumption (OCR) was immediately measured, and the extracellular acidification rate (ECAR) were detected following $3 \mathrm{~h}$ of incubation at $37^{\circ} \mathrm{C}$. The graph shows the ratio of OCR to ECAR. " $\mathrm{P}<0.05$ vs. control. Data are presented as the means $\pm \mathrm{SE}$ from 3 independent experiments. HCC, hepatocellular carcinoma; DIC, dicoumarol; OXA, oxaliplatin.
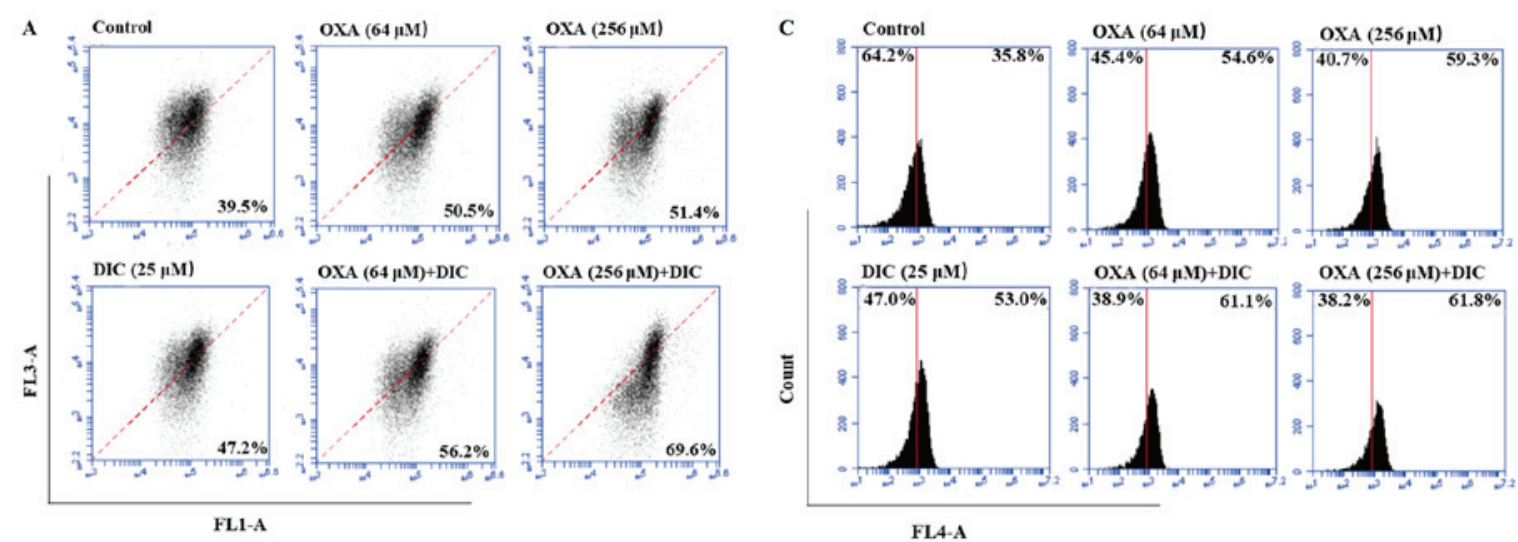

OXA $(64 \mu \mathrm{M})+\mathrm{DIC}$

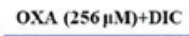

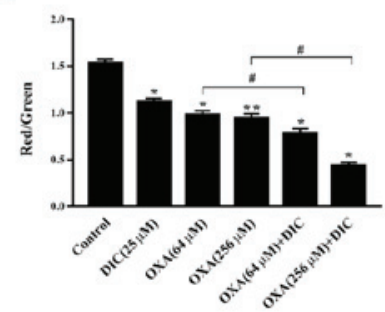

D

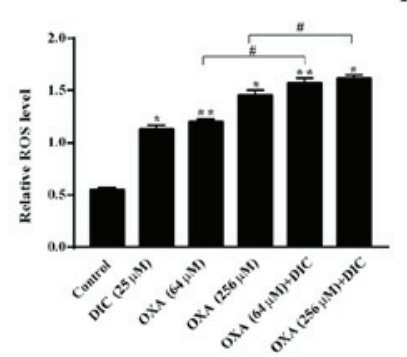

FLA-A

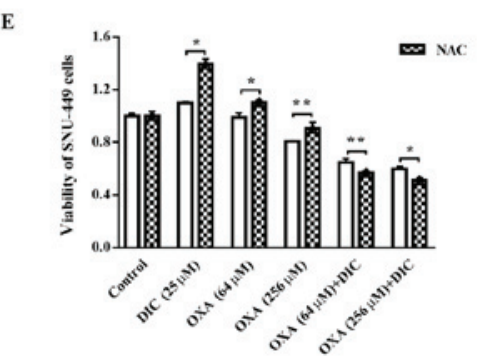

Figure 6. DIC promotes decline in MMP and increases the production of mtROS in HCC cells. SNU-449 cells were treated with DIC (25 $\mu$ M), OXA $(64$ and $256 \mu \mathrm{M})$, OXA $(64$ and $256 \mu \mathrm{M})$ and DIC $(25 \mu \mathrm{M})$ for $24 \mathrm{~h}$, and the $(\mathrm{A})$ mitochondrial membrane potential and $(\mathrm{C})$ mitochondrial ROS production were measured by flow cytometry and quantified. (B) The graph shows the change in mitochondrial membrane potential after DIC (25 $\mu \mathrm{M})$, OXA (64 and $256 \mu \mathrm{M})$, OXA $(64$ and $256 \mu \mathrm{M})$ and DIC $(25 \mu \mathrm{M})$ treated for $24 \mathrm{~h}$, the increased ratio of red fluorescence with green fluorescence represents the depolarization of the mitochondrial membrane. ${ }^{*} \mathrm{P}<0.05,{ }^{* *} \mathrm{P}<0.01$ vs. control; ${ }^{*} \mathrm{P}<0.05$ DIC treatment vs. no DIC treatment at the same concentration of $\mathrm{OXA}$. (D) The graph shows the quantification of mitochondrial ROS production after above treatments. ${ }^{*} \mathrm{P}<0.05,{ }^{* *} \mathrm{P}<0.01$ vs. control; ${ }^{*} \mathrm{P}<0.05 \mathrm{DIC}$ treatment vs. no DIC treatment at the same concentration of OXA. (E) Upon treatment of the SNU-449 cells with DIC ( $25 \mu \mathrm{M})$, OXA $(64$ and $256 \mu \mathrm{M})$, OXA $(64$ and $256 \mu \mathrm{M})$ and DIC $(25 \mu \mathrm{M})$ for $24 \mathrm{~h}$, the cell viability after NAC addition was assayed by MTT assay. ${ }^{*} \mathrm{P}<0.05,{ }^{* *} \mathrm{P}<0.01$ NAC treatment vs. no NAC treatment at the same concentration of DIC and OXA. Data are presented as the means \pm SE from 3 independent experiments. HCC, hepatocellular carcinoma; DIC, dicoumarol; OXA, oxaliplatin; MMP, mitochondrial membrane potential; ROS, reactive oxygen species; mt, mitochondrial. 


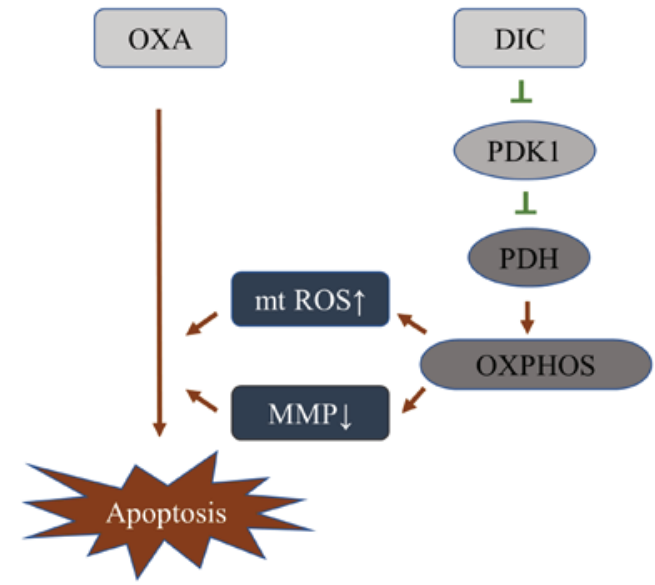

Figure 7. Schematic diagram of DIC changes the metabolic pattern of HCC cells by inhibiting PDK1 activity, thereby increasing its sensitivity to OXA. HCC, hepatocellular carcinoma; DIC, dicoumarol; OXA, oxaliplatin; MMP, mitochondrial membrane potential; ROS, reactive oxygen species; mt, mitochondrial.

the SNU449 cells. The above-mentioned results indicate that DIC can alter the metabolism of HCC cells and enhance oxidative phosphorylation.

DIC promotes a decrease in MMP and increases the production of mitochondrial ROS (mtROS) in HCC cells. Subsequently, the present study wished to determine the effects on the mitochondria due to the change in the metabolic mode in HCC cells, and the mechanisms through which DIC enhances the sensitivity of cells to apoptosis induced by OXA. It was found that the mitochondrial inner membrane potential decreased upon treatment with DIC compared to OXA alone treatment (Fig. 6A and B). An important byproduct of oxidative phosphorylation, mtROS, increased significantly following treatment with both DIC and OXA compared to OXA alone treatment (Fig. 6C and D). Notably, the viability of the SNU-449 cells treated with DIC $(25 \mu \mathrm{M})$ or OXA (64 and $256 \mu \mathrm{M}$ ) alone was restored when the cells were also treated with NAC ( $5 \mathrm{mM})$, an antioxidant that increases ROS scavenging (Fig. 6E). The above-mentioned results indicate that DIC increases HCC cell apoptosis by promoting the reduction of MMP and increasing the production of mtROS in HCC cells.

DIC alters the metabolic pattern of HCC cells by inhibiting PDK1 activity, thereby increasing its sensitivity to OXA. Based on the above-mentioned results, it was initially clarified that DIC can inhibit the activity of PDK1, and promote the metabolism of HCC cells towards oxidative phosphorylation, resulting in a decrease in mitochondrial membrane potential and an increase in ROS, thereby enhancing the sensitivity of HCC cells to OXA-induced apoptosis (Fig. 7).

\section{Discussion}

Consistent with previous findings by the authors in SKOV3 cells (16), the present study verified that DIC can inhibit PDK1 activity in HCC cells (Fig. 2E and 1F). However, it was also found that when DIC $(25 \mu \mathrm{M})$ was used in combination with
OXA, it enhanced the sensitivity of HCC cells to OXA-induced apoptosis (Fig. 2A and B), rather than the cytotoxicity directly caused by high-dose DIC (16). In addition, it was found that the higher the content of PDK1 in the cell, the more sensitive it seems to be the inhibitory effect of DIC (Fig. 2A, B and E). In the present study, DIC reduced the phosphorylation of $\mathrm{PDH}$ by inhibiting the activity of PDK1, which converted the metabolism of HCC cells to oxidative phosphorylation, leading to an increase in mtROS and a decrease in MMP, thereby increasing the sensitivity to apoptosis induced by the chemotherapeutic drug, OXA (Fig. 7).

HCC cells exhibit aerobic glycolysis, which can rapidly supply the basic molecules required for biosynthesis including the de novo generation of nucleotides, lipids and proteins, and can be diverted into multiple branching pathways that emanate from glycolysis (25), the necessary reducing equivalents and the acidic microenvironment to promote tumor growth and proliferation (26). In addition, this metabolic characteristic of tumor cells is also closely related to chemotherapeutic resistance (27). Tumor cells which lack functional AMPK or LKB1 demonstrate an enhanced susceptibility to OXPHOS inhibitors, as they fail to decrease energy consumption in response to the energetic stress induced by these agents, which then leads to an energetic crisis and cytotoxicity (28). Therefore, understanding the underlying mechanisms of aerobic glycolysis in tumor cells is necessary for the effectiveness of chemotherapeutic drugs $(25,27,29)$. In addition to the tumor cell's own metabolism which will affect its sensitivity to chemotherapeutic drugs, the macroenvironment includes the different tissues of the organism, capable of exchanging signals and fueling the tumor at 'a distance' (30). Clinically, an association between PKM2 expression levels and drug resistance has been reported (27,31-33). As a gatekeeper for aerobic glycolysis, PDK1 is highly expressed in HCC (34) (Fig. 1A). Therefore, the HCC cell lines, SNU-449 and SNU-387, were selected in the present study to examine the role of PDK1 in aerobic glycolysis and chemotherapeutic resistance.

PDK1 inactivates mitochondrial respiration through the phosphorylation of PDH (35). PDH catalyzes the oxidative decarboxylation of pyruvate to acetyl-CoA, one of the mechanisms of the entry into the tricarboxylic acid cycle of pyruvate in the mitochondria (36). Therefore, the inhibition of PDK1 activity by DIC promotes the entry of pyruvate into the mitochondria and the metabolic changes caused by it. The study by Sun et al demonstrated that increased PDH activity shifted metabolism from glycolysis to oxidative phosphorylation and decreased the hyperpolarization of the mitochondrial membrane potential, resulting in mitochondrial pore opening, allowing ROS and cytochrome c transport from the mitochondria to the cytoplasm, thereby inducing apoptosis through caspase activation (37). The present study wished to determine whether the inhibition of PDK1 activity could induce apoptosis or enhance sensitivity to chemotherapeutic drugs through this mechanism. It has been previously demonstrated that certain concentrations of DIC can induce the apoptosis of SKOV3 cells (16). Thus, the present study wished to determine whether the combined application of DIC for chemotherapy-insensitive and metabolically robust HCC cells would increase their apoptotic sensitivity. Therefore, the present study targeted 
PDK1, which is highly expressed in HCC cells, and verified its key regulatory role in metabolic processes, providing a theoretical basis for coping with the role of metabolic processes in the adaptive changes of tumors under stress, such as chemotherapeutic drugs.

The classic inhibitor of PDK1 is sodium dichloroacetate (DCA); however, its clinical trials has been terminated due to its severe side-effects (38-40). However, when used in co-treatment with the chemotherapeutic drug, paclitaxel (PTX), DCA markedly decreased cell autophagy, enhanced apoptosis and inhibited the proliferation of A549 and H1975 cells (41). Thus, the development of novel medications, which can improve the demerits of DCA, have been examined for the past 2 decades due to poor pharmacokinetics, and low potency and selectivity (34). It was previously found DIC that bound to the PDK1 lipoamide-binding pocket, suggesting it had the potential to inhibit PDK1 activity (16). In addition, DIC, as a clinically used drug for the prevention and treatment of thromboembolic diseases, has a guaranteed safety. The new use of 'old drugs' can also greatly reduce the cost of drug development.

In conclusion, the findings of the present study indicate that the inhibition of PDK1 may be a potential strategy for targeting metabolism in HCC with chemotherapy. DIC already has demonstrated clinical applications and its novel application in cancer treatment, as an 'old drug' that shows novel efficacy, brings new hope for antitumor therapy. Combined treatment with traditional chemotherapeutic drugs may also provide new insight into the treatment of HCC.

\section{Acknowledgements}

Not applicable.

\section{Funding}

The present study was supported by grants from the National Natural Science Foundation of China (nos. 81672948 and 81772794), the Jilin Provincial Research Foundation for Health Technology Innovation (no. 2019J009), the Jilin Provincial Research Foundation for the Development of Science and Technology Projects (no. 20191004004TC), the Jilin Provincial Industrial Innovation Project (no. 2018C052-7) and 'the Fundamental Research Funds for the Central Universities, Jilin University (JLU)'.

\section{Availability of data and materials}

The data that support the findings of this research are available from the corresponding author upon reasonable request.

\section{Authors' contributions}

HX performed most of the experiments and was responsible for writing the manuscript. YH conducted the data analysis. JM and YZ performed the animal experiments. YL provided materials, analyzed the data and revised the manuscript. LS and JS conducted the research, analyzed data and provided funding. All authors have read and approved the final version of the manuscript.

\section{Ethics approval and consent to participate}

All patient data were obtained from online datasets, and thus no ethics approval was required. All animal experiments were performed in accordance with the National Guidelines for Experimental Animal Welfare and with approval of the Animal Welfare and Research Ethics Committee at Jilin University (Changchun, China).

\section{Patient consent for publication}

Not applicable.

\section{Competing interests}

The authors have declared that no competing interest exists.

\section{References}

1. Wallace MC, Preen D, Jeffrey GP and Adams LA: The evolving epidemiology of hepatocellular carcinoma: A global perspective. Expert Rev Gastroenterol Hepatol 9: 765-779, 2015.

2. Ngan CY, Yamamoto H, Takagi A, Fujie Y, Takemasa I, Ikeda M, Takahashi-Yanaga F, Sasaguri T, Sekimoto M, Matsuura N, et al: Oxaliplatin induces mitotic catastrophe and apoptosis in esophageal cancer cells. Cancer Sci 99: 129-139, 2008.

3. Abdel-Rahman O: Revisiting oxaliplatin-based regimens for advanced hepatocellular carcinoma. Curr Oncol Rep 16: 394, 2014.

4. Ma J, Zeng S, Zhang Y, Deng G, Qu Y, Guo C, Yin L, Han Y, Cai C, $\mathrm{Li}$ Y, et al: BMP4 promotes oxaliplatin resistance by an induction of epithelial-mesenchymal transition via MEK1/ERK/ELK1 signaling in hepatocellular carcinoma. Cancer Lett 411: 117-129, 2017.

5. Yin X, Tang B, Li JH, Wang Y, Zhang L, Xie XY, Zhang BH, Qiu SJ, Wu WZ and Ren ZG: ID1 promotes hepatocellular carcinoma proliferation and confers chemoresistance to oxaliplatin by activating pentose phosphate pathway. J Exp Clin Cancer Res 36: 166, 2017.

6. Sheng J, Shen L, Sun L, Zhang X, Cui R and Wang L: Inhibition of $\mathrm{PI} 3 \mathrm{~K} / \mathrm{mTOR}$ increased the sensitivity of hepatocellular carcinoma cells to cisplatin via interference with mitochondrial-lysosomal crosstalk. Cell Prolif 52: e12609, 2019.

7. Morandi A and Indraccolo S: Linking metabolic reprogramming to therapy resistance in cancer. Biochim Biophys Acta Rev Cancer 1868: 1-6, 2017.

8. Fekir K, Dubois-Pot-Schneider H, Désert R, Daniel Y, Glaise D, Rauch C, Morel F, Fromenty B, Musso O, Cabillic F, et al: Retrodifferentiation of human tumor hepatocytes to stem cells leads to metabolic reprogramming and chemoresistance. Cancer Res 79: 1869-1883, 2019.

9. Choiniere J, Wu J and Wang L: Pyruvate dehydrogenase kinase 4 deficiency results in expedited cellular proliferation through E2F1-mediated increase of cyclins. Mol Pharmacol 91: 189-196, 2017.

10. Dai Y, Xiong X, Huang G, Liu J, Sheng S, Wang H and Qin W: Dichloroacetate enhances adriamycin-induced hepatoma cell toxicity in vitro and in vivo by increasing reactive oxygen species levels. PLoS One 9: e92962, 2014.

11. Xu Y, Gao W, Zhang Y, Wu S, Liu Y, Deng X, Xie L, Yang J, Yu H, Su J, et al: ABT737 reverses cisplatin resistance by targeting glucose metabolism of human ovarian cancer cells. Int J Oncol 53: 1055-1068, 2018.

12. Saunier E, Benelli $C$ and Bortoli S: The pyruvate dehydrogenase complex in cancer: An old metabolic gatekeeper regulated by new pathways and pharmacological agents. Int J Cancer 138: 809-817, 2016

13. Koukourakis MI, Giatromanolaki A, Sivridis E, Gatter KC and Harris AL; Tumor and Angiogenesis Research Group: Pyruvate dehydrogenase and pyruvate dehydrogenase kinase expression in non small cell lung cancer and tumor-associated stroma. Neoplasia 7: 1-6, 2005.

14. Wang J, Liu F, Ao P, Li X, Zheng H, Wu D, Zhang N, She J, Yuan J and Wu X: Correlation of PDK1 expression with clinicopathologic features and prognosis of hepatocellular carcinoma. OncoTargets Ther 9: 5597-5602, 2016. 
15. Battello N, Zimmer AD, Goebel C, Dong X, Behrmann I, Haan C, Hiller K and Wegner A: The role of HIF-1 in oncostatin M-dependent metabolic reprogramming of hepatic cells. Cancer Metab 4: 3, 2016.

16. Zhang W, Su J, Xu H, Yu S, Liu Y, Zhang Y, Sun L, Yue Y and Zhou X: Dicumarol inhibits PDK1 and targets multiple malignant behaviors of ovarian cancer cells. PLoS One 12: e0179672, 2017.

17. Chou TC: Drug combination studies and their synergy quantification using the Chou-Talalay method. Cancer Res 70: 440-446, 2010.

18. Rodea-Palomares I, Petre AL, Boltes K, Leganés F, Perdigón-Melón JA, Rosal R and Fernández-Piñas F: Application of the combination index (CI)-isobologram equation to study the toxicological interactions of lipid regulators in two aquatic bioluminescent organisms. Water Res 44: 427-438, 2010.

19. Xu H, Sun L, He Y, Yuan X, Niu J, Su J and Li D: Deficiency in IL-33/ST2 Axis Reshapes Mitochondrial Metabolism in Lipopolysaccharide-Stimulated Macrophages. Front Immunol 10: 127, 2019.

20. He Y, Meng H, Xu H, Fan L, Zhou Z, Xu B, Sun L and Gao Y: Regulation of integrated stress response sensitizes U87MG glioblastoma cells to temozolomide through the mitochondrial apoptosis pathway. Anat Rec (Hoboken) 301: 1390-1397, 2018.

21. Tang Z, Li C, Kang B, Gao G, Li C and Zhang Z: GEPIA: A web server for cancer and normal gene expression profiling and interactive analyses. Nucleic Acids Res 45 (W1): W98-W102, 2017.

22. Sun CC, Zhou Q, Hu W, Li SJ, Zhang F, Chen ZL, Li G, Bi ZY, Bi YY, Gong FY, et al: Transcriptional E2F1/2/5/8 as potential targets and transcriptional E2F3/6/7 as new biomarkers for the prognosis of human lung carcinoma. Aging (Albany NY) 10: 973-987, 2018

23. Lian Q, Wang S, Zhang G, Wang D, Luo G, Tang J, Chen L and Gu J: HCCDB: A Database of Hepatocellular Carcinoma Expression Atlas. Genomics Proteomics Bioinformatics 16 : 269-275, 2018

24. Emmanouilidi A and Falasca M: Targeting PDK1 for Chemosensitization of Cancer Cells. Cancers (Basel) 9: 9, 2017.

25. Liberti MV and Locasale JW: The warburg effect: How does it benefit cancer cells? Trends Biochem Sci 41: 211-218, 2016.

26. Zhang W, Zhang SL, Hu X and Tam KY: Targeting tumor metabolism for cancer treatment: is pyruvate dehydrogenase kinases (PDKs) a viable anticancer target? Int J Biol Sci 11: 1390-1400, 2015

27. Bhattacharya B, Mohd Omar MF and Soong R: The Warburg effect and drug resistance. Br J Pharmacol 173: 970-979, 2016.

28. Ngoi NYL, Eu JQ, Hirpara J, Wang L, Lim JSJ, Lee SC, Lim YC, Pervaiz S, Goh BC and Wong ALA: Targeting cell metabolism as cancer therapy. Antioxid Redox Signal 32: 285-308, 2020.
29. Icard P, Shulman S, Farhat D, Steyaert JM, Alifano M and Lincet H: How the Warburg effect supports aggressiveness and drug resistance of cancer cells? Drug Resist Updat 38: 1-11, 2018.

30. Amoedo ND, Obre E and Rossignol R: Drug discovery strategies in the field of tumor energy metabolism: Limitations by metabolic flexibility and metabolic resistance to chemotherapy. Biochim Biophys Acta Bioenerg 1858: 674-685, 2017.

31. Shin YK, Yoo BC, Hong YS, Chang HJ, Jung KH, Jeong SY and Park JG: Upregulation of glycolytic enzymes in proteins secreted from human colon cancer cells with 5-fluorouracil resistance. Electrophoresis 30: 2182-2192, 2009.

32. Guo W, Zhang Y, Chen T, Wang Y, Xue J, Zhang Y, Xiao W, Mo X and Lu Y: Efficacy of RNAi targeting of pyruvate kinase M2 combined with cisplatin in a lung cancer model. J Cancer Res Clin Oncol 137: 65-72, 2011.

33. Shi HS, Li D, Zhang J, Wang YS, Yang L, Zhang HL, Wang XH, Mu B, Wang W, Ma Y, et al: Silencing of pkm2 increases the efficacy of docetaxel in human lung cancer xenografts in mice. Cancer Sci 101: 1447-1453, 2010.

34. Jeoung NH: Pyruvate Dehydrogenase Kinases: Therapeutic Targets for Diabetes and Cancers. Diabetes Metab J 39: 188-197, 2015.

35. Qin L, Tian Y, Yu Z, Shi D, Wang J, Zhang C, Peng R, Chen X, Liu C, Chen Y, et al: Targeting PDK1 with dichloroacetophenone to inhibit acute myeloid leukemia (AML) cell growth. Oncotarget 7: 1395-1407, 2016.

36. Wada M, Horinaka M, Yasuda S, Masuzawa M, Sakai T and Katoh N: PDK1 is a potential therapeutic target against angiosarcoma cells. J Dermatol Sci 78: 44-50, 2015.

37. Sun W, Xie Z, Liu Y, Zhao D, Wu Z, Zhang D, Lv H, Tang S, Jin N, Jiang H, et al: JX06 Selectively inhibits pyruvate dehydrogenase kinase PDK1 by a covalent cysteine modification. Cancer Res 75: 4923-4936, 2015.

38. Tataranni T and Piccoli C: Dichloroacetate (DCA) and cancer: An overview towards clinical applications. Oxid Med Cell Longev 2019: 8201079, 2019.

39. Stacpoole PW, Martyniuk CJ, James MO and Calcutt NA Dichloroacetate-induced peripheral neuropathy. Int Rev Neurobiol 145: 211-238, 2019.

40. Stacpoole PW: The pharmacology of dichloroacetate. Metabolism 38: 1124-1144, 1989.

41. Lu X, Zhou D, Hou B, Liu QX, Chen Q, Deng XF, Yu ZB, Dai JG and Zheng H: Dichloroacetate enhances the antitumor efficacy of chemotherapeutic agents via inhibiting autophagy in non-small-cell lung cancer. Cancer Manag Res 10: 1231-1241, 2018.

This work is licensed under a Creative Commons Attribution-NonCommercial-NoDerivatives 4.0 International (CC BY-NC-ND 4.0) License. 